\title{
Effect of Resistance Exercise Intensity on the Strength and Lymphedema of Upper Extremity in Patients with Breast Cancer
}

Hyun-Jeong So ${ }^{1}$, Won-Seob Shin ${ }^{2}$

'Department of Physical Therapy, Graduate School of Daejeon University; ${ }^{2}$ Department of Physical Therapy, College of Health and Medical Science, Daejeon University, Daejeon, Korea

Purpose: The purpose of this study was to determine the effects of high and low resistance exercise using an elastic band on the strength and lymphedema of upper extremity in patients with breast cancer.

Methods: Seventeen female patients with breast cancer related lymphedema were randomly allocated to the high $(n=9)$ or low $(n=8)$ resistance exercise group. Both groups participated in the elastic band exercise program three times a week for eight weeks. For the high resistance exercise group (HR), the resistance was gradually increased, while maintaining constant intensity of exercise for the low resistance exercise group (LR). Assessments made include the upper extremity muscle strength and lymphedema before and after training.

Results: After the exercise program, the HR showed significantly improved shoulder flexion and elbow flexion strength variation compared to the $L R(p<0.05)$. Upper arm edema rate was significantly decreased in $H R(p<0.05)$, but the difference between the two groups was not significant.

Conclusion: These findings suggest that the elastic band exercise helps improve the strength and lymphedema of upper extremity in patients with breast cancer. In particular, high resistance exercise is more effective in improving muscle strength and does not exacerbate lymphedema, rather may improve upper arm edema if it is applied with a low elastic bandage or compression sleeve.

Keywords: Resistance exercise intensity, Lymphedema, Breast cancer, Elastic band

서 론

유방암 환자는 수술 및 방사선 치료 등의 치료과정에 따른 후유증으 로 흔히 수술 측 어깨 관절의 장애와 림프부종을 경험하게 된다.' 어 깨 관절 장애는 신체의 기능적 측면에서 일상 생활 동작 수행과 밀접 하게 연관됨으로써 ${ }^{2}$ 물리치료 분야에서 다양한 접근을 통해 중요하 게 다루어지고 있다.,4 유방암 환자에서 림프부종의 발생률은 평균 20-40\% 정도인 것으로 나타난다. ${ }^{5-7}$ 이는 지난 수십 년간 유방암 수술 방법의 발전에도 불구하고 여전히 흔하게 발생되고 있어, 수술 후 재 발 다음으로 심각하게 여겨지기도 한다.5.8 림프부종은 늘어난 부피 로 인한 신체적 불편함과 함께 관절 가동범위 제한과 같은 기능상실 을 유발할 수 있고, 봉와직염(cellulitis), 림프관염(lymphangitis)과 같은 면역과 관련된 문제를 일으킬 수 있다. ${ }^{\circ}$ 그 뿐만 아니라, 일단 발생하 면 완치가 되지 않아 철저한 자기 관리를 요구하고 생활 방식의 상당
한 변화를 초래하며 취미 생활, 직업 등을 포기하게 되어 불안, 우울 과 같은 정신적 문제를 야기하기도 한다.9

최근 유방암 환자의 높아진 생존율과 그에 따른 삶의 질 향상에 대 한 요구로 어깨 관절 장애 개선뿐만 아니라 림프부종 관리에 대한 중 요성이 더욱 강조되고 있다.5.8 운동은 유방암 환자의 어깨 관절 장애 개선과 림프부종 관리에서 중요한 중재 방법으로 알려져 있다.10,11 유 방암 수술 후 운동은 수술로 인한 유착 부위를 신장시켜 어깨 가동 성 소실 및 근력 약화를 예방하거나 완화하고 호흡과 근수축 증가로 인해 림프순환을 촉진시킨다. ${ }^{10}$ 또한 생활 방식의 변화나 비만 관리와 연관되어 간접적으로도 림프부종에 도움이 된다. ${ }^{12}$

한편, 기존의 유방암 환자를 위한 운동 프로그램은 대부분 스트레 칭과 유산소 운동, 저강도의 근력운동으로 한정되어 있는데, 이는 수 술 시 유발되는 손상에 대한 세밀한 분석의 부족과 함께 통상적으로 과격한 상지 운동이 림프부종을 유발하고 이를 더욱 악화시킨다는
Received Sep 16, 2015 Revised Oct 4, 2015

Accepted Oct 6, 2015

Corresponding author Won-Seob Shin

E-mail Shinws@dju.kr
Copylight (C) 2015 The Korea Society of Physical Therapy

This is an Open Access article distribute under the terms of the Creative Commons Attribution Non-commercial License (Http:// creativecommons.org/license/by-nc/3.0.) which permits unrestricted non-commercial use, distribution, and reproduction in any medium, provided the original work is properly cited. 
인식에서 비롯된 것으로 볼 수 있다.13,14 이러한 인식은 수술 측 팔의 지나친 활동 감소를 초래하게 되고, 결국 팔의 만성적인 근력 약화와 통증을 유발하며 활동 영역에서의 심리적 위축을 일으키게 된다.13 림프부종 팔의 운동 기능 손상 정도가 부종 자체보다, 부종과 관련된 심리적 이환에 더 크게 영향을 받는다는 연구 결과에 따라 ${ }^{5}$ 심리적 위축을 해소하는 것도 기능 회복을 위해 중요하게 고려되어야 할 것 이다. 고강도 운동에 대한 연구는 유방암 환자의 근력 강화와 부종에 대한 효과 검증과 함께 유방암 환자가 상지의 격렬한 사용을 요구하 는 활동에 참여할수 있는가에 대한 해답으로서 의의가 있다. 최근 연 구들에서 증등도 이상의 상지 근력 운동이 유방암 환자의 근력을 증 가시키고 삶의 질 향상과 관련된 기능 증진에 도움이 되며, 림프부종 에 안전함을 보고하고 있다.15-17 하지만 아직까지 관련 연구가 부족하 고 논쟁의 여지가 있는 상태이다. 특히 국내에 유방암 관련 림프부종 환자를 대상으로 한 저항운동에 대한 연구가 부족해18 한국인 유방 암 환자를 대상으로 저항 운동의 안정성과 효과에 대한 연구가 요구 된다.

운동 프로그램에서 흔히 사용되는 탄력밴드는 상해 위험이 적어 다양한 계층에 적용이 가능하며 유연성 및 근력증가, 평형성 증가에 도움이 된다. ${ }^{1920}$ 또한 다양한 동작을 유도할 수 있으며, 운동 강도의 조절이 용이한 점, 휴대가 간편하고 장소의 제한이 적다는 장점이 있 다. ${ }^{20}$ 한편 동시 수축의 효과는 어깨 관절의 근육 간 균형된 작용을 통 해 유방암 수술 후 발생하는 어깨 관절 장애를 개선시키고, 림프부종 상지에 붕대요법과 병행 시 반대압 효과를 증대시켜 부종감소에도 도움이 될 것이다.

따라서, 본 연구에서는 유방암 관련 림프부종 환자를 대상으로 어 깨 관절 장애의 특성을 고려한 탄력밴드 운동을 적용하였을 때, 운 동 강도에 따라 상지 근력과 림프부종에 미치는 효과를 비교하여 조 사하였다.

\section{연구 방법}

\section{1. 연구 대상}

본 연구는 C대학교병원에서 림프부종을 진단 받은 유방암 환자 20 명 을 대상으로 하였다. 연구대상자의 선정조건은 다음과 같다. 1) 편측 유방암 수술을 받은 여성으로서, 재활의학과 전문의에게 림프부종 진단을 받은 자, 2) 림프부종으로 물리치료를 4주 이상 받은 자(부종 의 유지기에 속하는 자),3) 상완신경총 손상과 같은 상지의 심각한 신 경 손상이 없는 자로 하였다. 수술을 받지 않았거나 양측 유방암 수 술을 받은 자, 항암화학요법을 진행 중인 자, 진행 중인 전이성 암이 있는 자, 심호흡계 심각한 이상이 있는 자는 연구에서 제외하였다. 대 상자들에게 연구의 목적과 방법을 설명하였고 연구 참여에 동의한
자들로 연구를 진행하였다.

\section{2. 실험 방법}

연구의 대상자는 고강도 운동군(high resistance exercise group)과 저 강도 운동군(low resistance exercise group)에 각각 10명씩 무작위 배정 되어 주 3 회 운동을 8 주간 실시하였고 중재 전후에 평가를 실시하였 다. 고강도 운동군은 운동 강도를 저강도로 시작하여 2주 간격으로 점차적으로 증가시켜 나갔다. ${ }^{21}$ 처음 1,2 주는 저강도로 운동을 시작 하였고 3,4 주에는 중등도 강도로 실시하였다. 5,6 주에는 고강도로 운동을 실시하였고 7,8 주에는 강도를 재측정하여 고강도에 맞게 적 용하여 실시하였다. 저강도 운동군은 8 주간 저강도로 운동을 지속 하였다. 모든 대상자는 운동 시 저탄력 붕대나 압박스타킹을 착용하 도록 하였다. 사후평가에는 고강도 운동군이 9 명, 저강도 운동군이 8 명으로 총 3 명이 탈락한 17 명이 최종연구에 참여하였다. 탈락한 3 명 은 직장문제 1 명, 근육통증으로 실험 포기 1 명, 저조한 출석률 1 명이 었다.

\section{1) 탄력밴드 운동 프로그램}

운동 프로그램은 유방암 수술 후 발생하는 어깨 관절 장애의 특성을 고려하여 흥부근 스트레칭과 견갑골 안정화, 상지 근력강화를 유도 할 수 있는 동작들로 구성하였다(Table 1).

준비 운동(warm-up)은 호흡운동(breathing exercise)과 스트레칭 (stretching exercise)으로 구성하였다.

본 운동(main exercise)은 견갑골 안정화(scapular stabilization)와 어 깨 근육 강화(shoulder muscle strengthening), 팔꿈치 근육 강화(elbow muscle strengthening)를 위한 동작으로 구성하였고, 양팔을 10 회씩 번갈아2세트 수행하도록 하였다. 견갑골 안정화 동작은 밴드를 등에 댄 상태로 양팔을 앞으로 뻗으면서 견갑골이 최대한 전인(protraction)되도록 하는 동작과, 양팔을 체간에 붙이고 팔꿈치를 구부려 밴

Table 1. Exercise program

\begin{tabular}{lll}
\hline & \multicolumn{1}{c}{ Type } & \multicolumn{1}{c}{ Duration } \\
\hline $\begin{array}{l}\text { Warm-up } \\
\text { Breathing exercise } \\
\text { Stretching exercise }\end{array}$ & 10 minutes \\
Main exercise & Neck Ms. / Pectoralis Ms. & \\
Scapular stabilization & Scapular protraction & 30 minutes \\
& Scapular retraction & 2 set \\
Shoulder Ms. Strengthening & Flexion & \\
Elbow Ms. Strengthening & Abduction & \\
& Flexion & \\
Cool-down & Extension & 5 minutes \\
\hline
\end{tabular}


드를 잡은 상태에서 팔꿈치를 고정하고 양손을 옆으로 벌려 어깨관 절 외회전이 일어나는 동시에 견갑골을 후인(retraction), 하강(depression)시키는 동작으로 구성하였다. 어깨 근육 강화 운동은 운동하는 팔의 동측 발로 밴드를 고정한 상태에서 어깨 굴곡과 외전을 실시하 도록 하였다. 팔꿈치 근육 강화 운동은 동측 발로 밴드를 고정한 상 태에서 팔꿈치 굴곡을 실시하고, 팔을 머리 위로 올린 상태에서 팔꿈 치 신전을 실시하였다. 팔을 올리고 있기 어려운 경우에는 반대쪽 발 로 밴드를 고정하고 팔을 뒤로 뻗어 팔꿈치 신전을 실시하였다.

정리운동(cool-down)으로 스트레칭과 호흡운동을 하며 운동을 마무리한다.

\section{2) 운동강도}

유방암 환자를 대상으로 한 저항 운동의 저강도, 중등도, 고강도에 대한 기준은 동작을 바른 자세로 각각 20 회 이상, 최대 15 회, 최대 10 회를 반복할 수 있는 강도를 검사하여 적용하였다. ${ }^{12}$ 강도의 조절은 대상자의 수준에 따라 탄력밴드의 길이와 단계 (노란색, 빨간색, 초록 색, 파란색)를 변화하여 맞추었다.

\section{3. 측정 방법}

\section{1) 상지 근력}

상지 근력은 근력측정기(Nicholas MMT Dynamometer 01160, Lafayette, USA)를 이용하여 표준화된 방법에 따라 유방암 수술 측 상지를 측정하였다.

측정자세는 상체를 기대고 앉은 자세로 팔을 앞으로 $90^{\circ}$ 로 들어 올 린 상태에서 어깨관절의 굴곡을 측정하고, 옆으로 $90^{\circ}$ 로 들어 올린 상태에서 외전을 측정하였다. 팔을 양 옆으로 편안히 내리고 전완부 를 $90^{\circ}$ 구부려 올린 상태에서 팔꿈치 관절의 굴곡과 신전을 측정하였 다. 측정치는 2 회 측정하여 평균값으로 하였으며 두 값의 차이가 $10 \%$ 이상인 경우 재검사를 실시하였다. 단위는 $\mathrm{kg}$ 으로 표시하였다.

\section{2) 림프부종}

림프부종의 측정은 손바닥이 위를 향하도록 팔을 앞으로 편 자세에 서, 상완골 외측 상과(lateral epicondyle of humerus)를 기준으로 팔꿈 치 관절 상부 $10 \mathrm{~cm}$ 의 상완부(upper arm)와 팔꿈치 관절 하부 $10 \mathrm{~cm}$ 의 전완부(forearm)의 둘레를 줄자를 이용하여 측정하였다. 양쪽 팔 을 각각 측정하였으며, 둘레 측정은 2 회 측정하여 평균값으로 하였 고, 부종률(edema rate)은 환측과 건측 둘레의 길이의 차를 건측 둘레 길이로 나눈 백분율로 계산하였다. ${ }^{22}$

\section{4. 자료분석}

본 연구의 모든 자료분석은 윈도우용 SPSS 18.0 ver.을 이용하였다. 모
든 결과 데이터들은 정규분포하여 평균과 표준편차로 통계분석하였 으며 그룹 내 실험 전후의 상지 근력과 림프부종의 변화를 대응표본 t-검정(paired t-test)을 통하여 분석하였다. 또한 고강도 운동군과 저강 도 운동군 간의 변화량 비교는 독립표본 t-검정(independent t-test)을 통하여 분석하였다. 모든 측정치의 통계학적 유의 수준 $\alpha=0.05$ 로 정 하였다.

\section{연구 결과}

\section{1. 연구 대상자의 일반적 특성}

실험 전 평가에서 두 군간에 나이, $\mathrm{BMI}$, 수술 후 경과 기간, 부종 기간, 절제한 림프절 개수, 수술 방법, 수술 부위, 암 병기, 보조치료 유무에 서 유의한 차이가 없었다(Table 2).

\section{2. 상지 근력에 대한 효과}

상지 근력의 실험 전 측정값은 고강도 운동군과 저강도 운동군 간에

Table 2. General characteristics of subjects

\begin{tabular}{|c|c|c|c|c|}
\hline & $\mathrm{HR}(\mathrm{n}=9)$ & $\operatorname{LR}(n=8)$ & & \\
\hline & $\begin{array}{l}\text { Mean } \pm \text { SD } \\
\text { or } n(\%)\end{array}$ & $\begin{array}{l}\text { Mean } \pm \text { SD } \\
\text { or } n(\%)\end{array}$ & tor $\chi^{2}$ & $\mathrm{p}$ \\
\hline Age (year) & $48.1 \pm 4.1$ & $50.0 \pm 4.1$ & -3.28 & 0.748 \\
\hline BMI (point) & $26.2 \pm 1.0$ & $26.8 \pm 1.6$ & -0.30 & 0.766 \\
\hline \multicolumn{5}{|l|}{ Post-operative } \\
\hline period (month) & $28.3 \pm 9.6$ & $33.4 \pm 11.0$ & -0.35 & 0.734 \\
\hline \multicolumn{5}{|l|}{ Post-lymphedema } \\
\hline period (month) & $21.6 \pm 7.9$ & $13.2 \pm 7.6$ & 0.71 & 0.490 \\
\hline \multicolumn{5}{|l|}{ Extent of lymph node } \\
\hline removal (number) & $17.1 \pm 2.2$ & $11.8 \pm 1.9$ & 1.84 & 0.086 \\
\hline \multicolumn{5}{|l|}{ Operation Method } \\
\hline Mastectomy & $6(67)$ & $5(63)$ & 0.03 & 0.858 \\
\hline Lumpectomy & $3(33)$ & $3(37)$ & & \\
\hline \multicolumn{5}{|l|}{ Treated side } \\
\hline Rt. & $4(44)$ & $5(63)$ & 0.55 & 0.457 \\
\hline Lt. & $5(56)$ & $3(37)$ & & \\
\hline \multicolumn{5}{|l|}{ Cancer Stage } \\
\hline 1 & $2(22)$ & $1(12)$ & 0.56 & 0.755 \\
\hline$\|$ & $3(33)$ & $4(50)$ & & \\
\hline III & $4(45)$ & $3(38)$ & & \\
\hline \multicolumn{5}{|l|}{ Radiation Therapy } \\
\hline Yes & $7(78)$ & $7(88)$ & 0.28 & 0.600 \\
\hline No & $2(22)$ & $1(12)$ & & \\
\hline \multicolumn{5}{|l|}{ Chemotherapy } \\
\hline Yes & $8(89)$ & $7(88)$ & 0.01 & 0.929 \\
\hline No & $1(11)$ & $1(12)$ & & \\
\hline
\end{tabular}

HR: High resistance exercise group, LR: Low resistance exercise group, BMl: Body mass index, Rt.: Right, Lt.: Left, n: Number. 
Table 3. The comparison of upper extremity muscle strength within and between groups

(Unit: kg)

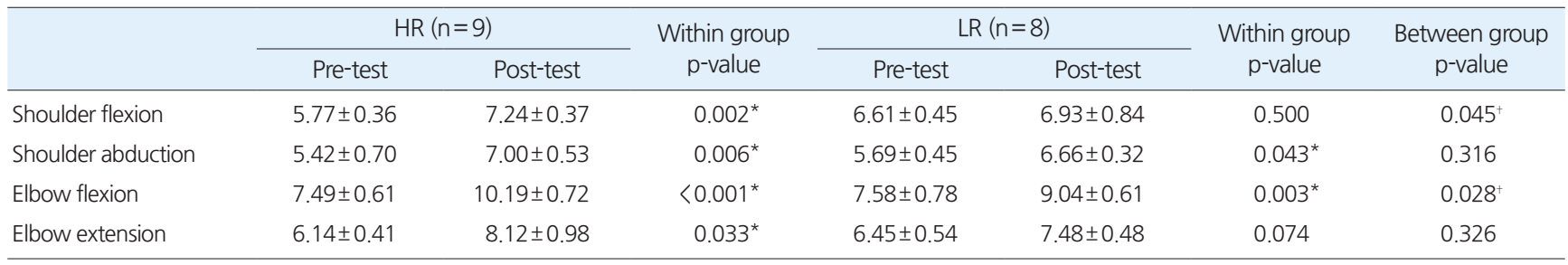

HR: High resistance exercise group, LR: Low resistance exercise group.

* significant difference within group, ${ }^{+}$significant difference between groups.

Table 4. The comparison of edema rate within and between groups

(Unit: \%)

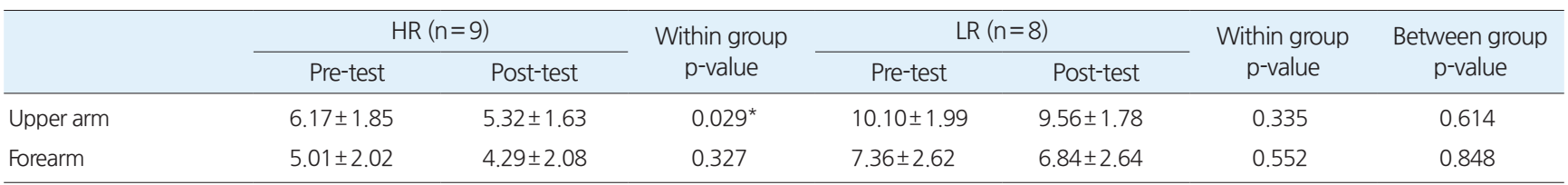

HR: High resistance exercise group, LR: Low resistance exercise group.

* significant difference within group.

유의한 차이가 없어 동질함을 확인하였다. 운동 프로그램 실시 후, 고 강도 운동군에서 어깨 관절의 굴곡 및 외전과 팔꿈치 관절의 굴곡 및 신전 근력이 유의하게 증가하였다 $(\mathrm{p}<0.05)$. 저강도 운동군에서는 어 깨 관절 외전과 팔꿈치 관절 굴곡 근력이 유의하게 증가하였다 ( $\mathrm{p}<0.05)$. 운동 프로그램 실시 후, 두 군 간에 근력의 변화량을 비교한 결과, 고강도 운동군이 저강도 운동군에 비해 어깨 굴곡 근력 변화량 과 팔꿈치 굴곡 근력 변화량이 유의하게 큰 것으로 나타났다 $(\mathrm{p}<0.05)$ (Table 3).

\section{3. 림프부종에 대한 효과}

림프부종의 실험 전 측정값은 고강도 운동군과 저강도 운동군 간에 유의한 차이가 없어 동질함을 확인하였다. 운동 프로그램 실시 후, 고 강도 운동군에서 상완부 림프부종률이 유의하게 감소하였고 $(\mathrm{p}<$ $0.05)$, 저강도 운동군은 유의한 변화가 없었다. 두 군 간 비교에서는 유 의한차이가 없었다(Table 4).

\section{고 찰}

유방암 환자의 상지 근력 약화는 $11-72 \%$ 로 보고되고 있으며, 수술을 비롯한 치료 과정 및 수술 후 경과 기간과 연관이 있는 것으로 나타 났다. ${ }^{23}$ 상지 근력 약화를 예방하기 위해서는 저항 운동이 필요하지 만, 유방암 환자의 경우 림프부종을 악화할 수 있다는 우려 때문에 그동안 적극적으로 실시하지 못하였다. 본 연구는 유방암 수술 환자 를 대상으로 저항 운동이 상지 근력과 림프부종에 미치는 영향과 안 정성을 알아보기 위해 시행하였다.

본 연구에서 저항 운동을 실시한 결과, 유방암 환자의 상지 근력
향상에 도움이 되는 것으로 나타났으며, 특히 고강도 운동이 저강도 운동에 비해 근력 향상에 더 효과적이었음을 알 수 있었다. Schneider 등 24 이 135 명의 유방암 환자와 전립선암 환자를 대상으로 한 선행 연 구에서 6 개월간 개인의 상태에 맞춰 중등도의 저항운동을 실시한 결 과 근 기능의 향상을 보였으며 이러한 효과는 암 치료 중인 경우와치 료 종료인 경우 모두에서 나타났다. Winters-Stone 등 25 이 106명의 폐 경기 이후의 유방암 생존자를 대상으로 저항 운동과 신장 운동의 효 과를 비교한 연구에서도 저항 운동이 최대 근력 향상에 효과가 있는 것으로 나타나, 암 환자의 근력 향상을 위해 저항운동이 적합하고 효 과적임을 알 수 있었다. 저항 운동의 경우 근골격계 손상과 피로 및 통증 등의 부작용이 유발될 수 있다. 유방암 환자를 대상으로 전통적 인 치료와 근력 운동을 비교한 연구에서 근력 운동 시 근골격계 손 상 발생이 높은 것으로 나타났으며, 특히 아직 부종이 발생하지 않은 림프부종 위험 환자들보다 현재 림프부종이 있는 환자들이 더 손상 빈도가 높은 것으로 나타났다.13 따라서, 유방암 환자, 특히 림프부종 환자를 대상으로 한 근력 운동 시에는 부종에 대한 영향과 함께 근 골격계 손상과 같은 부작용들을 고려해야 할 것이다. 본 연구에서는 운동 첫 회 실시 후에 1 명이 근육통으로 실험을 포기하였다. 이 대상 자는 광배근을 이용한 유방 복원술을 받은 여성이었다. 유방 복원술 의 경우 더 광범위한 부위에 반흔이 발생하고 근육의 배열이 달라진 다는 점에서 복원술을 받은 환자에게는 특성화된 동작과 강도를 고 려한 차별화된 운동 프로그램이 필요할 것으로 생각된다. 본 연구의 진행 동안, 이 여성을 제외하고 다른 부작용들은 발생하지 않았다.

본 연구에서 고강도 운동과 저강도 운동 시 림프부종의 변화를 측 정한 결과, 고강도 운동이 상완부 부종을 감소시키는 데 유의한 효과 가 있었다. 또한, 모든 강도의 운동에서 전완부 부종 측정 결과, 실험 
전후에 유의한 차이가 없어 운동으로 인하여 부종이 더 발생하지 않 았음을 알 수 있었다. 유방암 수술 관련 림프부종 환자를 대상으로 한 Hayes 등 12 의 선행 연구에서도 16 명의 저항 운동군 중 2 명이 림프 부종 소견이 없어져, 저항 운동이 상지 림프부종에 안전하며 최소한 부종을 악화시키지는 않는다고 하였다. Schmitz 등 ${ }^{15}$ 의 연구에서는 주 2 회 근력 강화 운동을 한 유방암 여성들은 운동을 하지 않은 군에 비해 1년 후에 림프부종이 악화된 비율이 두 배 가까이 적었고 부종 과 관련된 증상이 감소하였으며 근력이 향상된 것으로 나타났다. Lane 등 ${ }^{26}$ 은 유방암 생존자를 대상으로 상지의 격렬한 사용을 요구 하는 드래곤 보트 훈련(dragon boat traing)이 포함된 운동 프로그램 을 시행하였을 때, 양측 상지 모두 부피가 증가하였는데, 이는 근력의 유의한증가로 미루어 볼 때 부종 발생이 아닌 근육 부피의 증가에 의 한 결과라고 설명하였다. 본 연구에서 상완부에서만 둘레 감소를 보 였는데, 이는 전완부에 비해 상완부가 지방층이 두껍고 혈액 순환의 해부학적 구조에 차이가 있기 때문에, 림프액 감소와 지방 연소가 더 효율적으로 이루어졌을 것으로 추측되나 이를 증명하기 위해서는 특수한 형태의 측정 방법이 추가되었어야할 것이다.

림프 흐름은 림프선 자체의 수축성에 의한 내인성 원동력과 심장 수축, 호흡, 근육 운동, 혈관 박동, 장 운동 등에 의한 외인성 원동력에 의해 이루어진다. ${ }^{27}$ 유방암 수술 후 액와부 손상은 팔의 림프 배액 저 항을 일으키고, 이는 능동 수축성 림프선(acitively contractile lymphatic collectors)의 만성적인 작업 과부하(chronic work overload)로 이어져, 점차 수축성(contractility)이 감소되는 부전(failure)을 일으키게 된다. ${ }^{6}$ 결국, 수축성(contractility)이 손상된 부위를 따라 부종이 분포하게 되 는데, ${ }^{28,29}$ 예로 전완부 부종의 경우 근막하부의 림프관 손상에 유의 한 영향을 받는 것으로 나타났다. ${ }^{28}$ 림프선의 수축성 손상을 예방하 거나 이미 손상된 기능을 보강하기 위해 외인성 원동력의 역할이 중 요할 것이다. 운동은 피부와 피하부의 림프 흐름뿐만 아니라 근육의 림프 흐름을 촉진하며, ${ }^{30}$ 특히 고강도의 운동은 이를 더욱 보강하는 것으로 나타났다. 또한 장기간 운동에 의한 교감신경성 유출 증가, 근수축력 증가 및 혈관의 수축력 증가, 호흡증가와 같은 생리학적 변 화는 림프유입을 촉진하며, 림프관 재생과 휴면 중인 림프관의 동원 과 같은 긍정적인 림프계 변화를 가져올 수 있다. ${ }^{26}$ 하지만, 림프신티 그라피(lymphoscintigraphy)로 관찰한 실험에서 중등도의 운동 시 정 상인에서 림프액이 액와부로 흡수(axillar uptake)되는 것에 반해, 림 프부종 환자는 전완부의 피부 역류(forearm uptake, dermal backflow) 가 증가되는 것으로 나타나, ${ }^{32}$ 유방암 환자를 대상으로 한 저항 운동 의 적용 시 림프부종이 발생하거나 악화될 수 있다는 가능성을 염두 하고 신중히 실시하여야 할 것이다. 다행히 최근 연구들에서 중등도 이상의 저항 운동에 대한 안정성과 효용성이 보고되고 있으며, 본 연 구에서도 고강도의 운동이 유방암 환자의 상지 근력 강화에 효과적
이며 림프부종에도 안전한 것으로 나타나, 앞으로 체계적인 관리하 에 유방암 환자의 상지 기능 회복을 위해 적용될 수 있을 것으로 사 료된다.

한편, 본 연구의 결과를 해석하는 데 몇 가지 제한점이 있다. 연구 대상자가 한 병원에 국한되어 있고 대상자가 적어 연구결과를 모든 유방암 환자에게 일반화시키는 데 어려움이 있으며, 적용된 운동 프 로그램 외에 다른 저항 운동의 안정성을 일반화하는 데도 한계가 있 을 것이다.

본 연구에서는 유방암 관련 림프부종 환자에게 적용한 탄력밴드 운동의 운동 강도에 따른 효과를 알아보았다. 유방암 수술 환자에게 적용된 탄력밴드 운동은 상지 근력을 향상 시키고 저탄력 붕대나 압 박 스타킹을 착용한 상태에서는 림프부종에 안전한 것으로 나타났 다. 특히 고강도 운동은 저강도 운동보다 근력 향상에 더 효과적이며, 림프부종을 악화시키지 않고 오히려 상완부 림프부종을 개선시키는 데 효과가 있음을 알 수 있었다. 암환자에 대한 운동방법의 정확성과 운동처방의 세밀한 기술이 요구되며, 림프부종 발생이나 근골격계 손상과 같은 부작용을 점검하여 운동의 안정성을 평가하는 것이 필 요할 것이다.11,33 이를 바탕으로 향후 연구에서는 유방암 환자를 대상 으로 다양한 저항운동의 강도와 방법에 대한 연구가 이루어져야 할 것이다.

\section{REFERENCES}

1. Harrington S, Padua D, Battaglini C et al. Comparison of shoulder flexibility, strength, and function between breast cancer survivors and healthy participants. J Cancer Surviv. 2011;5(2):167-74.

2. Oh TY, Ha JY, Lee EJ et al. The effects of badminton on the shoulder and its correlation with the shoulder pain and disability index. J Kor Phys Ther. 2013;25(1):29-35.

3. Jang KH, Choi JD, Lee MH et al. A comparison of modified sling exercise and general isometric exercise in patients with shoulder impingement syndrome. J Kor Phys Ther. 2010;22(5):9-16.

4. Seo BD, Shin HS. The effect of self stretching exercise in patients with shoulder adhesive capsulitis. J Kor Phys Ther. 2010;22(1):19-26.

5. Pain SJ, Vowler SL, Purushotham AD. Is physical function a more appropriate measure than volume excess in the assessment of breast cancer-related lymphoedema (bcrl)? Eur J Cancer. 2003;39(15):2168-72.

6. Sakorafas GH, Peros G, Cataliotti L et al. Lymphedema following axillary lymph node dissection for breast cancer. Surg Oncol. 2006;15(3): 153-65.

7. Nielsen I, Gordon S, Selby A. Breast cancer-related lymphoedema risk reduction advice: A challenge for health professionals. Cancer Treat Rev. 2008;34(7):621-8.

8. Lee KW, Kim SB, Yoon KS et al. The risk factors associated with lymphedema after axillary dissection for breast cancer. Ann Surg Treat Res. 2006;71(2):85-90.

9. Jung HM, Jo MO. Factors influencing the emotional state of patients 
with lymphedema. J Korean Acad Nurs. 2006;36(5):845.

10. Bendz I, Fagevik Olsen M. Evaluation of immediate versus delayed shoulder exercises after breast cancer surgery including lymph node dissection-a randomised controlled trial. The Breast. 2002;11(3):241-8.

11. Cheema B, Gaul CA, Lane K et al. Progressive resistance training in breast cancer: A systematic review of clinical trials. Breast Cancer Res Treat. 2008;109(1):9-26.

12. Hayes S, Reul-Hirche H, Turner J. Exercise and secondary lymphedema: Safety, potential benefits, and research issues. Med Sci Sports Exerc. 2009;41(3):483-9.

13. Brown JC, Troxel AB, Schmitz KH. Safety of weightlifting among women with or at risk for breast cancer-related lymphedema: Musculoskeletal injuries and health care use in a weightlifting rehabilitation trial. Oncologist. 2012;17(8):1120-8.

14. Kilbreath SL, Refshauge KM, Beith JM et al. Progressive resistance training and stretching following surgery for breast cancer: Study protocol for a randomised controlled trial. BMC Cancer. 2006;6:273.

15. Schmitz KH, Ahmed RL, Troxel A et al. Weight lifting in women with breast-cancer-related lymphedema. N Engl J Med. 2009;361(7):664-73.

16. Cormie P, Pumpa K, Galvão DA et al. Is it safe and efficacious for women with lymphedema secondary to breast cancer to lift heavy weights during exercise: A randomised controlled trial. J Cancer Surviv. 2013; 7(3):413-24.

17. Kilbreath SL, Refshauge KM, Beith JM et al. Upper limb progressive resistance training and stretching exercises following surgery for early breast cancer: A randomized controlled trial. Breast Cancer Res Treat. 2012;133(2):667-76

18. Kim I. Literature review of exercise therapy effects in patients with breast cancer. Journal of Korean Society of Integrative Medicine. 2014;2(2):4958.

19. Shin YI. The effect of elastic band exercise based of pnf pattern on the $\mathrm{u} /$ e function in the spinal cord injury patient. J Kor Phys Ther. 2004;16(3): $459-66$.

20. Kim HJ, Lee SH, Kim KJ. The effects of elastic band training for injury prevention during winter training of golf. Exercise science. 2007;16(3): 305-16.

21. Kang JI, Moon YJ, Park SK et al. Effects of exercise program intervention on muscle activity in rotator cuff repair patient. J Kor Phys Ther. 2013; 25(2):56-63.
22. Kim SJ, Ro HL. Effects of manual lymph drainage on the edema and quality of life in lymphedema patients of maintenance phase. J Kor Phys Ther. 2009;21(4):89-96.

23. Hidding JT, Beurskens CH, van der Wees PJ et al. Treatment related impairments in arm and shoulder in patients with breast cancer: A systematic review. PLoS One. 2014;9(5):e96748.

24. Schneider CM, Hsieh CC, Sprod LK et al. Cancer treatment-induced alterations in muscular fitness and quality of life: The role of exercise training. Ann Oncol. 2007;18(12):1957-62.

25. Winters-Stone KM, Dobek J, Bennett JA et al. The effect of resistance training on muscle strength and physical function in older, postmenopausal breast cancer survivors: A randomized controlled trial. J Cancer Surviv. 2012;6(2):189-99.

26. Lane K, Jespersen D, McKenzie D. The effect of a whole body exercise programme and dragon boat training on arm volume and arm circumference in women treated for breast cancer. Eur J Cancer Care (Engl). 2005;14(4):353-8.

27. Gashev A, Zawieja D. Physiology of human lymphatic contractility: A historical perspective. Lymphology. 2001;34(3):124-34.

28. Stanton A, Mellor R, Cook G et al. Impairment of lymph drainage in subfascial compartment of forearm in breast cancer-related lymphedema. Lymphat Res Biol. 2003;1(2):121-32.

29. Modi S, Stanton AW, Mellor RH et al. Regional distribution of epifascial swelling and epifascial lymph drainage rate constants in breast cancerrelated lymphedema. Lymphat Res Biol. 2005;3(1):3-15.

30. Havas E, Parviainen T, Vuorela J et al. Lymph flow dynamics in exercising human skeletal muscle as detected by scintography. J Physiol. 1997; 504(1):233-9.

31. Lane K, Dolan L, Worsley D et al. Lymphoscintigraphy to evaluate the effect of high versus low intensity upper body dynamic exercise on lymphatic function in healthy females. Lymphat Res Biol. 2006;4(3):159-65.

32. Lane KN, Dolan LB, Worsley D et al. Upper extremity lymphatic function at rest and during exercise in breast cancer survivors with and without lymphedema compared with healthy controls. J Appl Physiol. 2007; 103(3):917-25.

33. McNeely ML, Campbell KL, Rowe BH et al. Effects of exercise on breast cancer patients and survivors: A systematic review and meta-analysis. CMAJ. 2006;175(1):34-41. 